\title{
APROVEITAMENTO DE RESÍDUOS AGROINDUSTRIAIS: PRODUÇÃO DE ENZIMAS A PARTIR DA CASCA DE COCO VERDE
}

\author{
MARIA ALICE ZARUR COELHO * \\ SELMA GOMES FERREIRA LEITE * \\ MORSYLEIDE DE FREITAS ROSA ** \\ ANGELA APARECIDA LEMOS FURTADO ***
}

\begin{abstract}
Investigou-se o aproveitamento da casca do coco verde, mediante fermentação semi-sólida, para produção de enzimas. A casca de coco foi previamente desidratada, moída e classificada em três diferentes granulometrias, ou seja, 14, 28 e 32 mesh Tyler. Todas as enzimas obtidas tiveram sua produção máxima na faixa de 24 e 96 horas, o que corresponde ao tempo de produção industrial corrente. Cada granulometria produziu complexos enzimáticos ricos em diferentes atividades. O estudo realizado validou a hipótese do aproveitamento do resíduo da casca do coco verde na produção de enzimas por Aspergillus niger.
\end{abstract}

\section{INTRODUÇÃO}

Nos últimos anos, especial atenção vem sendo dada para minimização ou reaproveitamento de resíduos sólidos gerados nos diferentes processos industriais. Os resíduos provenientes da indústria de alimentos envolvem quantidades apreciáveis de casca, caroço e outros. Esses materiais, além de fonte de matéria orgânica, servem como fonte de proteínas, enzimas e óleos essenciais, passíveis de recuperação e aproveitamento.

O aumento crescente no consumo do coco verde e a vocação natural para a industrialização de sua água vêm aumentando a geração de rejeito (casca de coco), que corresponde a cerca de $85 \%$ do peso do fruto. Segundo dados fornecidos pela Companhia de Limpeza Urbana do Rio, COMLURB, o coco corresponde a cerca de $80 \%$ de todo o lixo coletado na

* Professora da Escola de Química da Universidade Federal do Rio de Janeiro, RJ.

** Pesquisadora da Embrapa Agroindústria Tropical, Fortaleza - CE.

(e-mail: morsy@cnpat.embrapa.br).

*** Pesquisadora da Embrapa Agroindústria de Alimentos, Rio de Janeiro, RJ.

(e-mail: afurtado@ctaa.embrapa.br). 
orla marítima. Paralelamente, as indústrias que processam água-de-coco geram volumes significativos e crescentes do mesmo material, que atualmente, é enterrado em lixões e aterros, causando problemas, especialmente em grandes centros urbanos (ROSA, 1998).

O rejeito da indústria convencional do coco maduro pode ser usado como combustível para caldeiras, ou na manufatura de cordoalha, tapetes, estofamentos e capachos. Estudos mais recentes sugerem ainda a utilização do resíduo da casca na agricultura intensiva, principalmente no cultivo de plantas ornamentais e hortaliças (MURRAY, 2001; OHLER, 1986). No entanto, a alta umidade (cerca de $85 \%$ ) e as características da fibra do coco imaturo reduzem seu aproveitamento em relação a casca do coco maduro.

Tornar viável o aproveitamento da casca do coco verde, gerado tanto como resíduo industrial quanto como lixo urbano, significaria mais uma alternativa de lucro para os sítios de produção.

O desenvolvimento tecnológico mundial avança cada vez mais no caminho dos processos biotecnológicos, devido à irreversível tendência de prevalência das políticas ambientais. Nesse sentido, a substituição de processos químicos convencionais por processos enzimáticos torna o desenvolvimento e 0 aprimoramento desta tecnologia de suma importância. Enzimas são catalisadores orgânicos, responsáveis pelas milhares de reações bioquímicas envolvidas nos processos biológicos dos sistemas vivos. As enzimas apresentam ampla utilização na indústria alimentícia, principalmente em processos de maceração de vegetais e frutas para a produção de néctares e purês, no processamento de produtos cárneos (tenderização), na produção de queijos, na extração e clarificação de sucos de frutas e vinho, na desengomagem de fibras naturais e na recuperação de óleos vegetais. São utilizadas também nas indústrias de papel e celulose, têxtil (biopolimento do jeans) e na produção de rações animais (COELHO, 1993; CUNHA, 1999). As enzimas, tais como poligalacturonase e pectinase, entre outras, são utilizadas nas indústrias de suco de frutas para diminuir a viscosidade do mesmo, contribuindo para o aumento do seu fluxo nos processos que empregam membrana (MUTLU et al., 1999; VAILANT et al., 1999). No campo da comercialização de enzimas, o Brasil é ainda, basicamente consumidor de produtos importados, apesar de todo o seu potencial.

O mercado mundial da tecnologia enzimática movimenta, anualmente, cerca de 2 bilhões de dólares (NORDISK, 1996). Tal montante justifica-se pelo interesse gerado por processos que envolvem tecnologia de baixo custo energético, com menor impacto ambiental e que utiliza matériasprimas renováveis, adequando-se ao reaproveitamento de sub-produtos da agroindústria. 
Uma das alternativas para a casca de coco verde poderia ser o seu aproveitamento em processos fermentativos, como a produção de enzimas. Como a maioria dos rejeitos agroindustriais, este material contém grande quantidade de compostos como celulose, hemicelulose, pectina e outros, não havendo necessidade de grandes complementações nutricionais para 0 adequado desenvolvimento microbiano. Estes compostos funcionam como indutores para a produção de enzimas extracelulares, tais como celulases, xilanases, pectinases e outras.

No presente trabalho verificou-se a viabilidade técnica da produção de enzimas, mediante fermentação semi-sólida, utilizando a casca do coco verde como matéria-prima.

\section{MATERIAL E MÉTODOS}

A casca de coco verde, oriunda de produtores de Santa Cruz (RJ), foi desidratada em secador de bandeja, a $35{ }^{\circ} \mathrm{C}$ por 48 horas. A seguir foi triturada em moinho de facas e classificada em peneiras, conforme granulometria especificada na Tabela 1.

TABELA 1 - FAIXAS DE GRANULOMETRIA DE CASCA DE COCO VERDE UTILIZADAS

\begin{tabular}{cccc}
\hline Granulometria & Tyler (Mesh) & Abertura $(\mathrm{mm})$ & Umidade $(\%)$ \\
\hline 1 & 14 & 1.19 & 8.4 \\
2 & 28 & 0.59 & 7.0 \\
3 & $<32$ & $<0.50$ & 5.2 \\
\hline
\end{tabular}

As três granulometrias foram utilizadas em diferentes experimentos. Optouse pela fermentação semi-sólida, principalmente devido a possibilidade de aproveitamento do resíduo e da relação entre o reator de volume reduzido/unidade de substrato convertido.

A linhagem de Aspergillus niger utilizada neste estudo foi isolada do solo, sendo proveniente da coleção de culturas do Departamento de Engenharia Bioquímica da Universidade Federal do Rio de Janeiro (UFRJ). Procedeuse a ativação da linhagem por repiques sucessivos em gelose CzapeckDox inclinada.

Solução de nutrientes, contendo $0.9 \%$ de sulfato de amônio e $0.1 \%$ de fosfato de potássio, foi elaborada com a finalidade de fornecer fonte de nitrogênio $(\mathrm{N})$, enxofre $(\mathrm{S})$ e fósforo $(\mathrm{P})$ necessários para o crescimento dos microrganismos. 
A fermentação foi conduzida utilizando-se a razão $1: 1$ de casca de coco/solução de nutrientes, de modo a identificar qual granulometria permitiria o melhor crescimento do microrganismo e produção de enzimas.

Para as fermentações foram preparados 15 frascos erlenmeyer $(250 \mathrm{~mL})$, sendo 5 para cada granulometria. Em cada erlenmeyer foram colocados $15 \mathrm{~g}$ da casca do coco e $15 \mathrm{~mL}$ da solução nutriente. Os meios foram autoclavados por 5 minutos a $1 \mathrm{~atm}$ e o inóculo empregado consistiu de $10^{6}$ esporos de Aspergillus niger por grama de meio sólido utilizado. A duração total destas fermentações foi de sete dias, com amostragem diária.

Visando verificar a influência da flora microbiana, natural da casca do coco verde, na produção de enzimas foram conduzidos, também, experimentos com o substrato não autoclavado e sem inoculação.

Em intervalos de 24 horas, as enzimas foram extraídas pela adição de $100 \mathrm{~mL}$ de tampão acetato (pH 5,0), agitação em shaker a $160 \mathrm{rpm}$ e temperatura de $30 \stackrel{\circ}{ } \mathrm{C}$ por 30 minutos. A seguir, procedeu-se filtração a vácuo, em funil de Büchner, usando papel de filtro ADVANTEC TOYO $5 \mathrm{C}$ $(185 \mathrm{~mm})$ para separar o resíduo da fermentação do sobrenadante (extrato enzimático). O sobrenadante foi filtrado a vácuo em filtro Milipore, usandose membrana de $0,5 \mu \mathrm{m}$ para retirada dos esporos. Estocou-se o extrato enzimático a $-20 \stackrel{\circ}{ } \mathrm{C}$ para análises posteriores.

Para a determinação das atividades enzimáticas, todas as soluções de substratos foram previamente mantidas por 10 minutos nas temperaturas de reação. A atividade de cada enzima foi expressa em unidade $/ \mathrm{mL}$ de extrato enzimático, a saber

- $\quad$ Xilanase - uma unidade de xilanase corresponde a $1 \mu \mathrm{mol}$ de xilose liberada por minuto a $60^{\circ} \mathrm{C}$ e $\mathrm{pH} 4,2$ (PINTO, 1998);

- $\quad$ Carboximetilcelulase - uma unidade de CMCase corresponde a $1 \mu \mathrm{mol}$ de glicose liberada por minuto em $\mathrm{pH} 4,8$ e $50{ }^{\circ} \mathrm{C}$ (PINTO, 1998);

- $\quad$ Protease - uma unidade de atividade foi definida como o aumento de 0,01 de absorbância, que a amostra apresente em relação ao branco por minuto a $32{ }^{\circ} \mathrm{C}$ e $\mathrm{pH} 5$ (PINTO, 1998);

- Poligalacturonase - uma unidade de pligalacturonase foi definida como a quantidade de enzima que libera $1 \mu \mathrm{mol}$ de ácido galacturônico, a partir de solução $0,25 \%(p / v)$ de ácido poligalacturônico, por minuto, a $45^{\circ} \mathrm{C}$ e pH 4,4 (COELHO, 1993). 


\section{RESULTADOS E DISCUSSÃO}

\subsection{INFLUÊNCIA DA GRANULOMETRIA}

As Figuras 1 a 4 apresentam os perfis de produção enzimática, obtidos ao longo do tempo, para as granulometrias estudadas.

\section{FIGURA 1 - PRODUÇÃO DE PROTEASES PARA AS GRANULOMETRIAS ESTUDADAS}

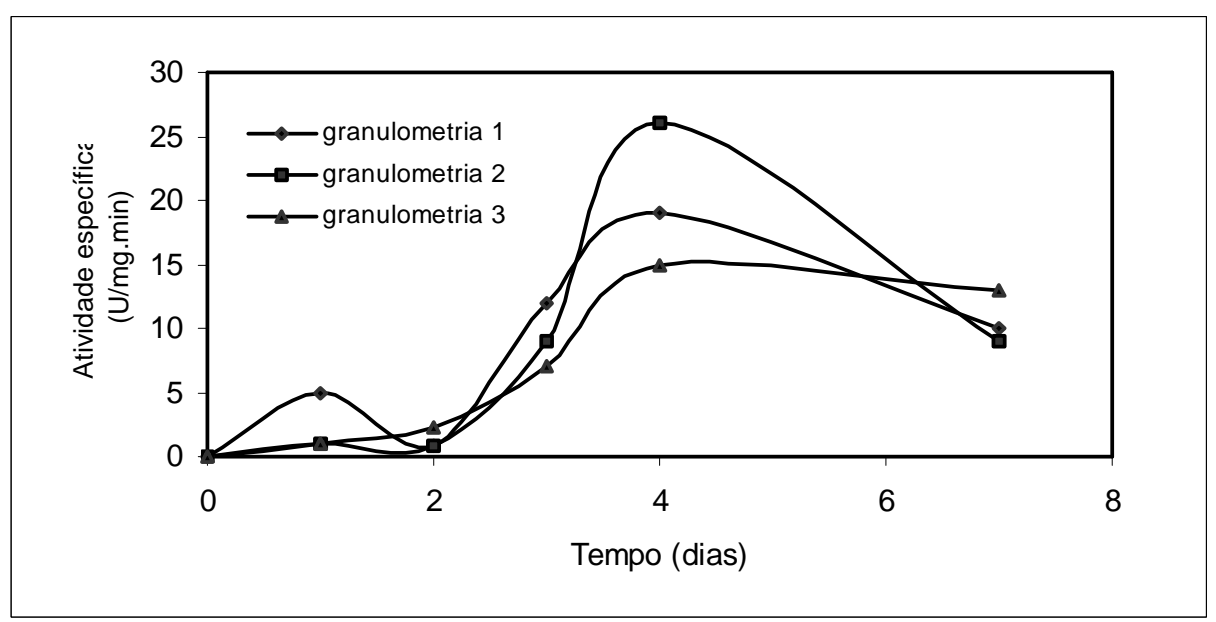

FIGURA 2 - PRODUÇÃO DE PECTINASES PARA AS GRANULOMETRIAS ESTUDADAS

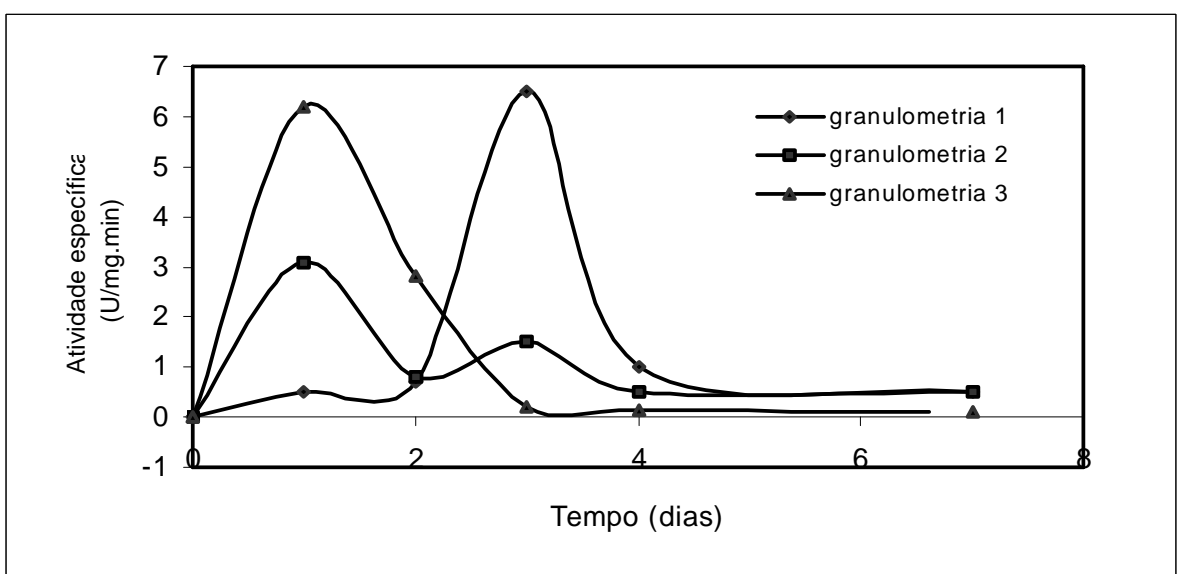




\section{FIGURA 3 - PRODUÇÃO DE CELULASES PARA AS GRANULOMETRIAS ESTUDADAS}

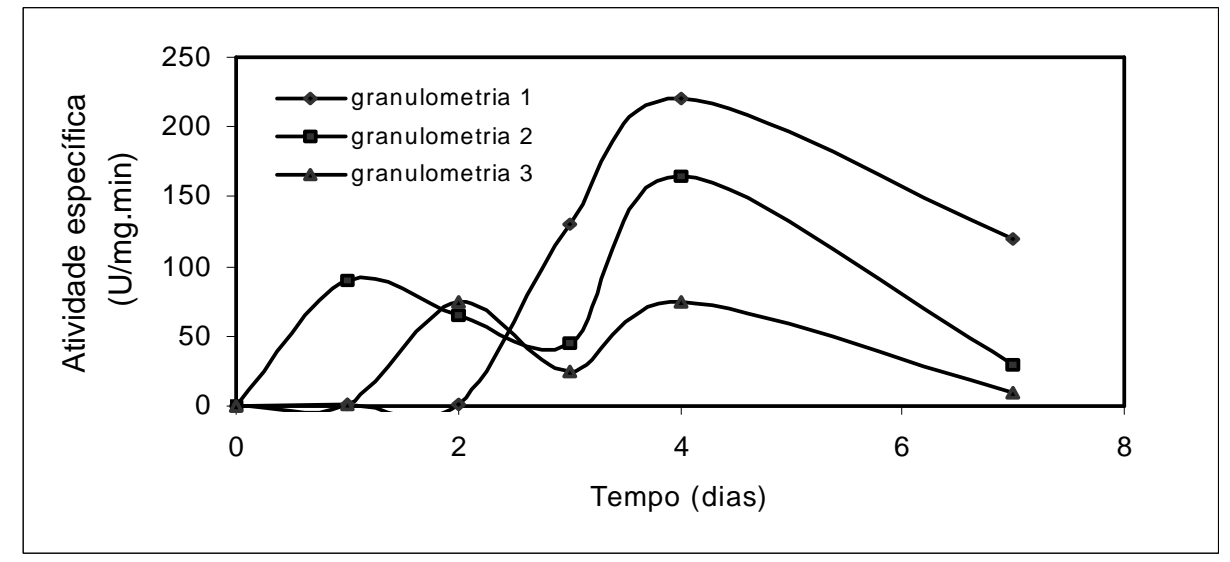

\section{FIGURA 4 - PRODUÇÃO DE XILANASES PARA AS GRANULOMETRIAS ESTUDADAS}

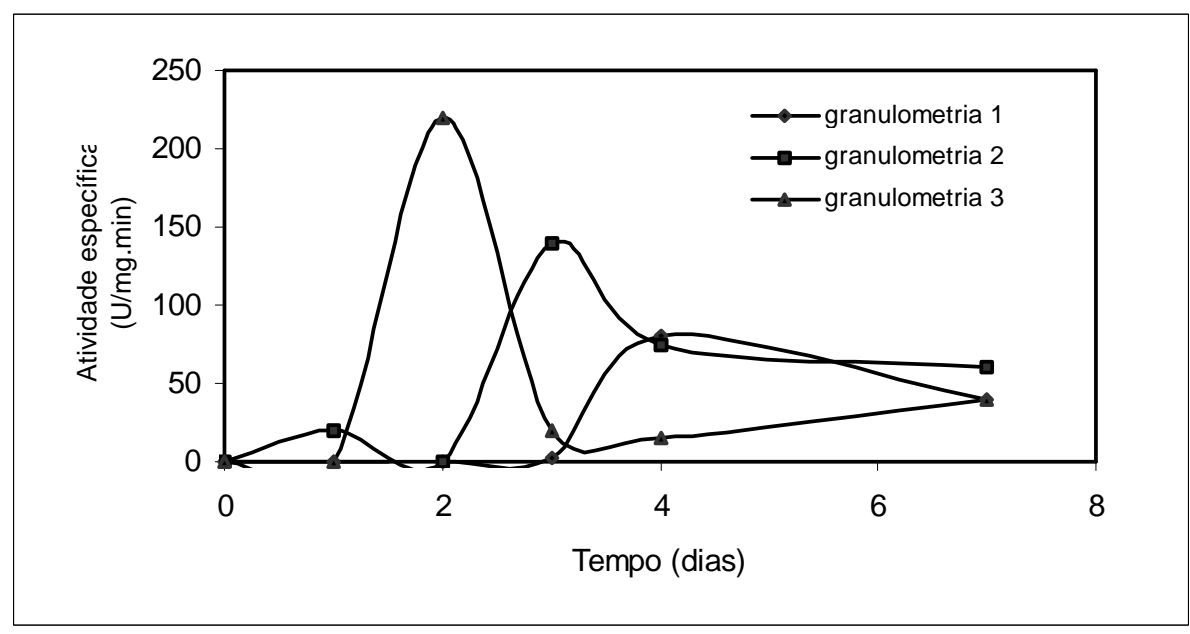

De acordo com os resultados obtidos, a produção enzimática está relacionada com a granulometria, da seguinte forma:

- Granulometria 1 (Tyler 14)

Observou-se a formação de complexo enzimático rico em pectinase, com pico de produção verificado no $3^{\circ}$ dia (Figura 2), e celulase, com pico de produção detectado no $4^{\circ}$ dia (Figura 3). A produção de pectinase ocorreu 
de forma tardia quando comparada com a granulometria 3 , cujo máximo de produção foi atingido no 1 - dia. Este retardamento da produção de pectinase deve-se, provavelmente, a menor área interfacial específica da granulometria 1. Adicionalmente, foi formada pequena quantidade de xilanase, conseguindo-se produção intermediária de protease (Figuras $4 \mathrm{e}$ 1 , respectivamente).

- Granulometria 2 (Tyler 28)

A granulometria 2 apresentou resultados intermediários para a produção de xilanase e celulase. Houve baixa produção de pectinase e elevada produção de protease, com máximo de produção detectado no $4^{\circ}$ dia (Figura 1), quando comparada às demais granulometrias.

- Granulometria 3 (Tyler 32)

Verificou-se a formação de complexo enzimático rico em pectinase, com pico de produção no 1ำ dia (Figura 2), e xilanase, com máximo de produção obtido no $2^{0}$ dia (Figura 4). Detectou-se também atividade celulásica e proteásica, em níveis inferiores às demais granulometrias.

A queda na produção das enzimas, observada nos perfis de atividade específica, normalmente é atribuída a ação proteolítica ou a instabilidade das moléculas enzimáticas durante o processo produtivo.

Todas as enzimas obtidas apresentaram produção máxima entre 24 e 96 horas, o que corresponde ao tempo de produção industrial corrente. Considerando que o biorreator utilizado era bastante simples, sem aeração e sem agitação, acredita-se que a otimização do processo poderia elevar a produtividade nos casos estudados.

Em função da aplicação desejada pode-se escolher a granulometria mais adequada, visto que as diferentes granulometrias produziram complexos enzimáticos ricos em diferentes atividades. A Tabela 2 apresenta os principais complexos enzimáticos obtidos para cada faixa granulométrica estudada.

TABELA 2 - PRODUÇÃO DE ENZIMAS EM DIFERENTES GRANULOMETRIAS

\begin{tabular}{c|c}
\hline Granulometria & Principais enzimas produzidas \\
\hline 1 & Pectinase/Celulase \\
2 & Protease \\
3 & Pectinase/Xilanase \\
\hline
\end{tabular}




\subsection{INFLUÊNCIA DA FLORA MICROBIANA NATURAL}

Observou-se crescimento microbiano nos meios não esterilizados, com aspecto macroscópio diferenciado daqueles encontrados nos meios inoculados com Aspergillus niger. Este microrganismo, naturalmente encontrado pode ser advindo da matéria-prima ou do ambiente.

A Figura 5, que apresenta o desempenho dos meios inoculados e não inoculados na produção de proteína após sete dias de fermentação, evidencia que, para as três granulometrias, a produção de proteínas foi superior no meio não esterilizado. Pode-se dizer então que o microrganismo presente na casca do coco é, aparentemente, produtor potencial de proteínas e, provavelmente de enzimas.

\section{FIGURA 5 - CONCENTRAC̣ÃO DE PROTEÍNA TOTAL APÓS SETE DIAS DE FERMENTAÇÃO}

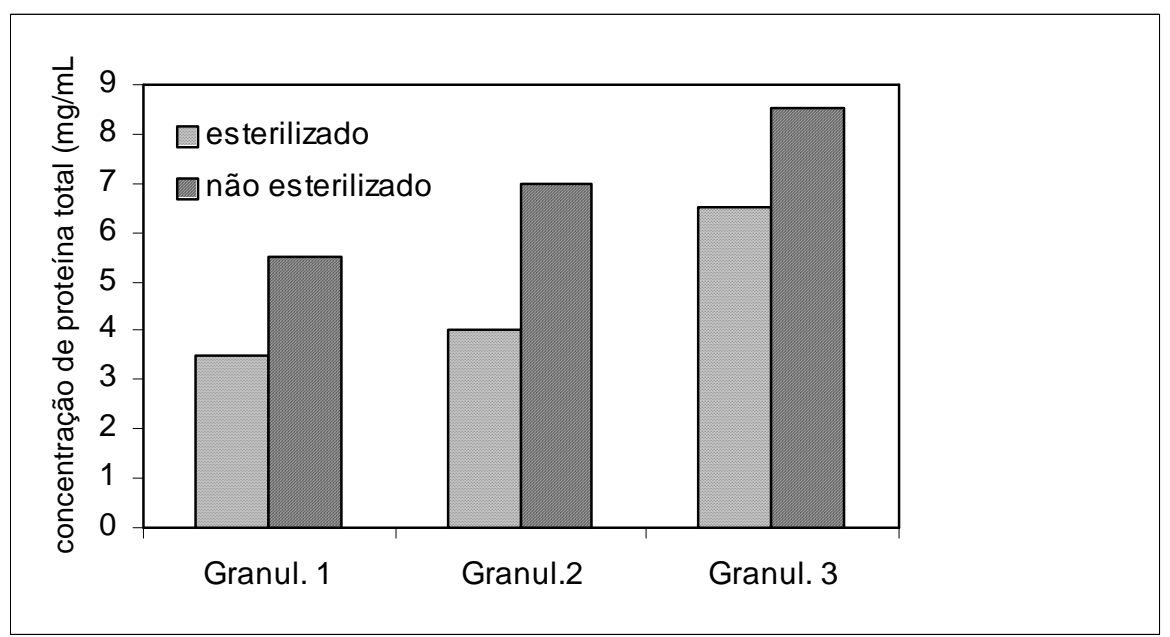

A Tabela 3 apresenta as principais enzimas produzidas pela flora microbiana natural, para cada granulometria, ao final de sete dias de fermentação.

\section{TABELA 3 - PRINCIPAIS ENZIMAS PRODUZIDAS PELA FLORA MICROBIANA NATURAL}

\begin{tabular}{c|c|c|c}
\hline Tipos de & Granulometria 1 & Granulometria 2 & Granulometria 3 \\
\cline { 2 - 4 } enzimas & Pectinase e protease & pectinase & Pectinase e celulase \\
\hline
\end{tabular}


Conforme os resultados obtidos verifica-se que há necessidade de esterilizar o meio, caso a influência de microrganismos naturais na produção de enzimas seja indesejada.

A possibilidade de se conduzir o processo utilizando o microrganismo nativo, sem prévia inoculação ou esterilização, pode representar redução de custos. Entretanto, o controle microbiológico do processo é prejudicado, bem como a qualidade do produto final, uma vez que não se pode garantir o desenvolvimento da mesma linhagem fúngica a cada batelada.

\section{CONCLUSÃO}

O estudo realizado validou a hipótese do aproveitamento do resíduo da casca do coco verde na produção de enzimas por Aspergillus niger.

Todas as enzimas obtidas tiveram sua produção máxima no período entre 24 e 96 horas, o que corresponde ao tempo de produção industrial corrente.

A possibilidade de produção de enzimas por microrganismos nativos não deve ser descartada, pois de acordo com os dados apresentados, obtevese bons resultados para algumas enzimas, após o sétimo dia de fermentação, em meio não esterilizado.

\section{Abstract}

The utilization of immature coconut peel as substrate for enzyme production by solid state fermentation was investigated. The coconut peel was previously dehydrated, milled and classified in three distinct granulometries: 14, 28 and 32 mesh Tyler. All the enzymes obtained had its maximum production in 24 to 96 hour interval, which correspond to the current industrial production time. Each granulometry produced rich enzymatic complexes with different activities. This study validates the hypothesis of benefit immature coconut peel as raw material for enzyme production by Aspergillus niger.

\section{REFERÊNCIAS}

1 COELHO, M. A. Z. Purificação da poligalacturonase produzida por Aspergillus niger 3T5B8. Rio de Janeiro, 1993. 124 p. Dissertação (Mestrado), Curso de Pós-Graduação em Tecnologia de Processos Químicos e Bioquímicos, Escola de Química, UFRJ.

2 CUNHA, R. T. Aplicação de enzimas em processos industriais têxteis. Rio de Janeiro, 1999. p. 1-22. Monografia, Curso de PósGraduação em Tecnologia de Processos Químicos e Bioquímicos, Escola de Química, UFRJ. 
3 MURRAY, N. P. Caracterización y evaluación agronómica del residuo de fibra de coco: un nuevo material para el cultivo en sustrato. Valencia, 2001. 228 p. Tesis (Doctorales) en Ciencias Químicas, Escuela Técnica Superior de Ingenieros Agrónomos, Departamento de Química de la Universidad Politecnica de Valencia.

4 MUTLU, M.; SARIOGLU, K.; DEMIR, N.; MERAL, T.E.; ACAR, J. The use of commercial pectinase in fruit juice industry. Part I: Viscosimetric determination of enzyme activity. Journal of Food Engineering, Abingdod, Oxon, v.41, p. 147-150, 1999.

5 NORDISK S/A. Biotimes. [S.I.], 1996.

6 OHLER, J. G. El cocotero: árbol de la vida. Roma: FAO, 1986. 348 p. (Estudios FAO de Producción y Protección Vegetal, n. 57).

7 PINTO, G. A. S. Produção de uma mistura enzimática hidrolítica por Aspergillus niger 3T5B8 em fermentação submersa. Rio de Janeiro, 1998. 100 p. Dissertação (Mestrado), Curso de PósGraduação em Bioquímica, Instituto de Química, Departamento de Bioquímica, UFRJ.

8 ROSA, M.F. Alternativas para o uso da casca de coco verde. Rio de Janeiro: Rede local da Embrapa Agroindústria de Alimentos, 1998. 10 p. (Programa 10 - Extração, colheita, pós-colheita, transformação e preservação de produtos agrícolas. Subprojeto 10.1999.083-03).

9 VAILANT, F.; MILLAN; P.; O'BRIEN; G.; DORNIER; M., DECLOUX, M.; REYNES, M. Crossflow microfiltration of passion fruit juice after partial enzymatic liquefaction. Journal of Food Engineering, Abingdod, Oxon, v.42, p. 215-224, 1999.

\section{Agradecimentos}

Os autores agradecem a participação dos alunos Adriana Gomes Moret, Alessandra de Andrade Lima, Daniela Sayão Vieira, Flávia Cavaleiro Costa, Natalie Jorge Gonçalves e Vladimir Ferreira Cabral na condução deste trabalho. 